\title{
Implicit and Explicit Attitudes and Interracial Interaction: The Moderating Role of Situationally Available Control Resources
}

\author{
Wilhelm Hofmann \\ University of Würzburg \\ Tobias Gschwendner \\ University of Koblenz-Landau \\ Luigi Castelli \\ University of Padova \\ Manfred Schmitt
University of Koblenz-Landau
}

\begin{abstract}
The present research examined whether implicit and explicit racial attitudes predict interracial interaction behavior differently as a function of situationally available control resources. Specifically, we investigated how implicit attitudes (Implicit Association Test) and explicit attitudes (Blatant/Subtle prejudice) were related to interracial interaction behaviors of Italians toward an African interviewer (Study 1) and of Germans toward a Turkish interviewer (Study 2). For half of the interview questions, participants' control resources were reduced via a memory task. Across both studies, the Race IAT was more predictive of behavior when participants were taxed than when untaxed. Conversely, explicit attitudes were somewhat more predictive under full resources. Taken together, our findings suggest that available control resources moderate the predictive validity of implicit and explicit attitudes.
\end{abstract}

KEYWORDS control resources, implicit and explicit attitudes, intergroup behavior, interracial interaction

UNDER many circumstances, social behavior is determined by impulses such as spontaneous evaluations rather than by reasoned attitudes and beliefs. Just imagine yourself standing in line at the supermarket either after an exhausting workday with a long list of unfinished business in mind or after your weekly yoga course and a relaxing afternoon at the local wellness center. Being eventually served by a foreign cashier, in which of the two cases will your interaction behavior more likely be influenced by your spontaneous evaluation of foreigners, and

\footnotetext{
$\overline{\text { Author's note }}$

Address correspondence to Wilhelm Hofmann, Universität Würzburg, Lehrstuhl für Psychologie II, Röntgenring 10, 97070 Würzburg Germany [email: hofmannw@psychologie.uni-wuerzburg.de]
} 
when will it be based instead on your reasoned attitudes and beliefs?

A significant proportion of psychological research over the last decade concerns the distinction between so-called implicit and explicit attitudes and their roles in behavior determination. Implicit attitudes can be understood as evaluations that are spontaneously and effortlessly activated upon the mere encounter of an attitude object and may serve as 'quick guides' to behavior that do not depend on people's awareness and control (e.g. Greenwald \& Banaji, 1995). In contrast, explicit attitudes are assumed to reflect capacityconsuming reasoned evaluations that influence action through deliberation and motivation (e.g. Fazio \& Olson, 2003).

Implicit and explicit attitudes seem to share some systematic overlap on average (e.g. Hofmann, Gawronski, Gschwendner, Le, \& Schmitt, 2005) and the conditions that determine the magnitude of the relationship have become increasingly well understood (Hofmann, Gschwendner, Nosek, \& Schmitt, 2005; Nosek, 2005). Furthermore, preliminary results from a meta-analysis suggest that both implicit and explicit measures contribute significantly to the prediction of a large range of behaviors across domains (Poehlman, Uhlmann, Greenwald, \& Banaji, 2006). However, even though theoretical models about the relative influence of implicit and explicit measures on behavior exist, the situational boundary conditions of these measures' predictive validity have rarely been investigated. The purpose of the present research is to empirically test one key moderator of implicit and explicit measures' predictive validity, situationally available control resources, in the domain of interracial interaction.

The distinction between implicit and explicit attitudes can be linked to a variety of dual-process (e.g. Fazio \& Towles-Schwen, 1999), or dualsystem theories (e.g. Strack \& Deutsch, 2004) that distinguish two modes or two systems of information processing. These theories share a conception that the two modes or systems will be differentially influential on perception, judgment, and action but differ somewhat with regard to whether implicit and explicit attitudes are seen as structurally different. For instance, the MODE model (Fazio \& Towles-Schwen,
1999) distinguishes between spontaneous and deliberate processes by which an attitude may influence judgments and behavior. Spontaneous processes are understood as immediate reactions toward an attitude object upon encountering the object. In contrast, deliberate processes are characterized by effortful considerations about the pros and cons of a certain behavior. Whereas implicit measures are assumed to tap into the spontaneous processing stage, explicit measures are assumed to usually reflect more elaborate judgments from the deliberate processing stage (Fazio \& Olson, 2003). Hence, the emphasis of the MODE model is on implicit and explicit measures tapping into different processing stages of an underlying attitude. Regarding behavior prediction, the model assumes that laborious deliberate processes will only be influential in overriding spontaneous processes and guiding behavior if a person has sufficient resources available to engage in deliberate processing and is motivated to do so. If a person does not have sufficient resources to deliberate or is not motivated to use them, spontaneous processes driven by implicit attitudes should prevail.

In contrast to the MODE model, most other dual-process theories propose that implicit and explicit measures reflect structurally distinct mental representations (e.g. Smith \& DeCoster, 2000; Strack \& Deutsch, 2004; Wilson, Lindsey, \& Schooler, 2000). From the perspective of Strack and Deutsch's (2004) Reflective-Impulsive Model (RIM) of social behavior, for instance, implicit attitudes are part of the impulsive system which operates via associative processes of spreading activation and elicits behavior by activating relevant behavioral schemas. Explicit attitudes, on the other hand, are part of the reflective system in which behavior is elicited as the result of a higher-order decision or 'reasoned action' process (Strack \& Deutsch, 2004). Importantly, the reflective system may finally execute behavior by activating behavioral schemas relevant to the intended action plan. Thus, even though both systems operate in parallel and involve different processes by which behavior is elicited, the RIM assumes a final, common pathway of behavioral execution: the activation of behavioral schemas (see also Norman \& Shallice, 1986). Most important for the present considerations, 
the relative impact with which the two systems affect behavior may depend on certain boundary conditions or moderator variables. Since the reflective, but not the impulsive system, requires substantial amounts of executive control resources for efficient functioning (Strack \& Deutsch, 2004), behavior should primarily be elicited by the impulsive system when control resources are scarce, i.e. when behavioral schemas are predominantly triggered by spontaneously activated attitudes. Conversely, the reflective system's potential to generate action plans and override behavioral schemas activated by the impulsive system should increase when sufficient control resources are available and, as a consequence, the relative impact of the impulsive system on behavior should lessen. Taken together, despite their differences on the structural level, both the MODE model and the RIM converge on the prediction that implicit and explicit measures should have a differential impact on behavior as a function of available control resources.

Indirect evidence for these assumptions can be derived from research showing the differential validity of implicit and explicit measures in the prediction of spontaneous versus controlled behavior (e.g. Asendorpf, Banse, \& Mücke, 2002; Dovidio, Kawakami, \& Gaertner, 2002; Dovidio, Kawakami, Johnson, \& Johnson, 1997; Fazio, Jackson, Dunton, \& Williams, 1995). These studies demonstrated that implicit attitudes (and personality traits; Asendorpf et al., 2002) mainly predict spontaneous behavior, whereas explicit attitudes mainly predict controlled behavior. However, this line of research was primarily concerned with the impact of implicit and explicit attitudes on various behaviors that are supposed to differ a priori with regard to controllability. For example, in the Dovidio et al. (1997) study on Whites' interracial interaction behavior toward Blacks, the rate of eye blinking and the percentage of visual contact toward the Black interaction partner-both considered nonverbal behaviors that are difficult to control-were best predicted by Whites' implicit attitudes as measured with a subliminal priming paradigm. In contrast, participants' selfreported evaluations of their Black interaction partner were best predicted by explicitly assessed modern racism scores.

Although the distinction between spontaneous and controlled behaviors is parsimonious and intuitively intriguing, such a clear-cut pattern of results did not emerge in all studies on differential predictive validity. For instance, McConnell and Leibold (2001) reported significant positive correlations between implicit attitudes toward Blacks as measured with the Implicit Association Test (IAT; Greenwald, McGhee, \& Schwartz, 1998) and a variety of behaviors such as speaking time, social comments and smiling that arguably contain controlled elements as well. Likewise, a variety of behaviors usually considered spontaneous such as forward leaning, body openness, or seating distance, were not reliably related to IAT scores. Findings like these point to the possibility that behavior determination by implicit and explicit attitudes is more dynamic and complex than previously assumed, and that the above findings on predictive validity may be somewhat limited by the fact that 'there is not an established taxonomy that identifies deliberative from spontaneous behaviors' (Dovidio et al., 2002, p. 66). Most important, as available control resources were not manipulated or assessed in the above line of research, these studies provide no direct evidence for the hypothesis that a given behavior may be influenced to different degrees by implicit and explicit attitudes depending on available control resources.

The main goal of the present research was to test this central assumption of dual-process or dual-system theories in two studies on interracial interaction behavior of Italians toward Africans (Study 1) and Germans toward Turks (Study 2). In each study, we first assessed implicit and explicit attitudes toward the outgroup by using an IAT (Greenwald, et al., 1998) as an implicit measure, and the Blatant and Subtle Prejudice Scale (BSPS; Pettigrew \& Meertens, 1995) as an explicit measure. Then we created conversations around race-neutral topics closely following the Dovidio et al. (1997, 2002) paradigm in which participants interacted both with an outgroup and an ingroup conversation partner. As in those studies, behavior toward the ingroup 
partner was used as a baseline in order to control for individual differences in interaction styles. Situationally available control resources were manipulated as a within-subjects factor by imposing a memory task (e.g. Reisberg, 1983) on participants during half of the interview questions. The interaction sequences were videotaped and later coded on a variety of behavioral measures adapted from prior research on interpersonal interaction (Asendorpf et al., 2002; Dovidio et al., 1997; McConnell \& Leibold, 2001).

Our primary interest was in the prediction of racial biases, i.e. differences in interaction behavior toward the outgroup partner relative to the ingroup partner. In accordance with a dualprocess or dual-system framework, we expected that the IAT would be a stronger predictor of behavior in the memory load condition and have a weaker impact in the high resources condition. Conversely, we expected that the BSPS would yield higher predictive validity when full control resources were available.

\section{Study 1}

\section{Method}

Participants A total of 86 (72 female, 14 male) first-year psychology students from an introductory psychology course at the Department of Psychology in Padova, Italy, participated in exchange for course credit. Gender proportions mirror the high number of females registered in psychology at the University of Padova. The age of participants ranged between 18 and 49 years $(M=21.00, S D=4.34)$. For one participant, the video camera did not register behavior due to a technical problem.

Materials and procedure The study consisted of two supposedly unrelated parts. Participants were informed that they would take part in two different experiments that contained tasks often used in social psychological research and were going to be run in two separate laboratories by different experimenters. In the first part, introduced as a computer experiment on perception and classification, participants completed the implicit and explicit attitude measures. In the second part, introduced as an interview practice session, participants' interracial behavior toward African males was observed. We used only male confederates and male stimuli for the attitude measures because prejudice against males has been found to be stronger and more pervasive (Eagly \& Kite, 1987), and therefore we reasoned that using males would increase the power of the test of our hypotheses.

Implicit attitude measures Implicit attitudes were assessed with a Race IAT, using facial images of eight African and eight Italian adult males as target stimuli and eight positive and eight negative affective nouns as attribute stimuli (see Appendix). Images were $90 \times 128$ pixel color photos of African and Italian male young adults taken from different web pages. Following the Race IAT, a control Flower-Insect IAT (Greenwald et al., 1998) was administered, using eight pictures of flowers and insects, respectively, and the same affective nouns as for the Race IAT. The control IAT was included in order to evaluate the specificity of the Race IAT with regard to the prediction of interracial behavior.

Each IAT consisted of seven blocks in a fixed sequence: in the first block, participants classified target stimuli into the categories 'African' and 'Italian' or 'flowers' and 'insects', respectively. In the second block, participants classified attribute stimuli into the categories 'positive' and 'negative'. In the third practice and the fourth test block, targets and attributes had to be classified simultaneously such that African faces (or insects, respectively) and positive nouns were assigned to the same key. In the fifth block, the key assignment for the attribute dimension was reversed. In the sixth practice and seventh test block, African faces (insects) and negative nouns were assigned to the same key. As we were interested in individual differences in implicit attitudes, order of combined blocks and key assignment were held constant for both IATs (Banse, Seise, \& Zerbes, 2001).

The practice and test blocks had 32 trials each, such that each stimulus was presented once. Target and attribute stimuli were presented randomly in an alternate fashion without replacement. IAT scores were computed according 
to the improved scoring algorithm proposed by Greenwald, Nosek, and Banaji (2003). In order to estimate the reliability of the IAT, we created four mutually exclusive subsets of all combined-task trials via an odd-even split and calculated IAT scores separately for each subset. The internal consistency of subsets amounted to .90 for the Race IAT and .88 for the FlowerInsect IAT (see Table 1).

Explicit attitude measure An Italian translation of the BSPS (Pettigrew \& Meertens, 1995) by Arcuri and Boca (1996) assessed participants' explicit attitudes toward Africans on 5-point rating scales. Since all items loaded on a single common factor $(\lambda=5.50)$ as indicated by a screeplot and since the BSPS subscales were highly correlated $(r(84)=.69, p<.001)$, we combined all 20 items into a single scale score (BSPS). ${ }^{1}$ One item ('If Africans would only try harder, they could be as well off as Italian people') showed a very low item-total correlation of .08 and was therefore removed from the scale $(\alpha=.85)$.

Interracial interaction After completing the first part of the study, participants were met by a second female experimenter and escorted to another room with two chairs in it at a standardized distance of 9 feet $(2.8 \mathrm{~m}) .{ }^{2}$ Participants were seated on the chair in the back of the room, facing the side of the entrance door. A video camera was situated behind the interviewer's chair, facing the participant's chair, and another camera was situated behind the participant's chair directed toward the interviewer's chair.

Participants were led to believe that-due to a collaborative effort of the Psychology and Sociology Departments, sociology students from a research methods course were given the possibility to gain experience in interviewing. For this reason, two students from this course would be asking two short questions each about topics related to studying and living in Padova. A sample question was given together with the reassurance that questions would be easy to answer and not too intimate. Furthermore, participants were given the following information:

From the view of a social psychologist, one interesting research question is how an interview is influenced by ongoing mental occupation: in order to study these effects, you will be given a word list shortly before some of the interview questions are asked. Your task will be to read this list and to think of these words during the interview in order to be able to recall as many words as possible after the interview question has been answered.

In sum, the cover story allowed us to confront participants with two confederates, one African and one Italian, and to impose half of the

Table 1. Means, standard deviations, reliabilities, and intercorrelations for implicit and explicit measures in Study 1 and Study 2

\section{(1)}

$(.90)$
$.34 * *$
-.07
-0.62
0.48

(1) RACE IAT

(2) BSPS

(2) BSPS

(3) Flower-Insect IAT

$S D$
Study 1

(2)

$* p<.05 ; * * p<.01$.

Notes: $N=86$ in Study 1 and $N=77$ in Study 2. Reliabilities $(\alpha)$ are in parentheses in the main diagonals. IAT = Implicit Association Test; BSPS = Blatant Subtle Prejudice Scale. 
interview questions with a memory task aimed at reducing available control resources.

After the experimenter had given the instructions and obtained participants' consent that their responses may be videotaped, she started both video cameras and the first interview sequence began. ${ }^{3}$ In the memory load condition (see below for details), participants were first presented with a list of words to remember. In the case of no memory task (full resources condition), the experimenter immediately moved on to the next point in the script.

The experimenter then left the room, and after a brief pause the first confederate entered the room, introduced himself, sat down on the confederate chair and asked the first interview question. Confederates were instructed to let participants respond without interruption until they indicated the end of the answer. If necessary, the confederate asked one or more follow-up question(s) until approximately two minutes had passed. At the end of the interview sequence, the confederate left the room and the experimenter entered again.

In the case of a preceding memory task, the experimenter handed participants a blank sheet and asked them to recall and write down as many words as possible from the list within one minute. Then, in all cases, participants were asked to rate the difficulty of answering the interview question and the interviewer's competence in asking the question on 7-point scales. ${ }^{4}$

After the questionnaire, the next interview sequence began until all four sequences had been finished. Questions 1 and 2 were asked by the first confederate, questions 3 and 4 by the second confederate. The order of confederate race (African vs. Italian) was counterbalanced. There was one memory task per confederate, and the position of the task-at each interviewer's first or second question-was balanced across confederates. At the end of the study, participants were given course credit. A detailed debriefing took place in front of the class after data collection was over.

Manipulation of control resources A memory task was chosen to reduce available control resources instead of other possible dual-task paradigms frequently employed such as tracking a point of light, because we reasoned that mere mental occupation would interfere least with the interracial interaction behavior displayed concurrently by our participants. In the memory load condition, participants were given one minute to read and remember as many words as possible from one of two parallel lists of 20 words taken from Roediger and McDermott (1995). There was one list per confederate and the order of lists was held constant. In the full resources condition, participants were not confronted with a memory task. In order to provide an achievement incentive for the memory task, participants were told that they would be receiving sweets at the end of the interview session (which they actually did) and that the amount received would depend on the number of words recalled. We did not inform participants about the exact minimum number of words that had to be remembered for receiving sweets because we wanted to avoid setting a fixed goal standard that may have given rise to success or failure experiences during the interview sequences.

Confederates The team of confederates consisted of two male African and three male Italian confederates who were hired for the duration of the experiment. Confederates were comparable in size, age, attractiveness, clothing, and did not wear glasses. They underwent practice in order to ask the interview questions in a comparable way and to behave similarly toward the participants. Confederates were unaware of the hypotheses of the study, memory load condition, and participants' implicit and explicit attitude scores.

Interview questions We used four easy and familiar questions about student life: (a) advantages and disadvantages of eating in the university dining hall vs. eating at home, (b) advantages and disadvantages of living with one's parents vs. living alone, (c) consequences of crowded seminars and lectures on the quality of teaching, and (d) an evaluation of cultural life in Padova. The order of questions was balanced such that each question was asked equally often at the 
first, second, third, and fourth position of the interview session. Furthermore, question order was balanced with regard to memory load condition and confederate race.

Codings of behavior Participants' digitized interaction behavior from the first 90 after a question was asked was coded by one trained coder who was unaware of experimental conditions and study hypotheses. Coding reliability was assessed via independent coding of 80 randomly selected interview sequences by a second coder. Videos were watched once without coding first. Then coders filled out a global rating of the participants' behavior consisting of five bipolar adjective ratings on a 7-point scale (from -3 to +3 ) with a midpoint of zero. The positive and negative poles were: polite-impolite, talkativequiet, pleasant-unpleasant, relaxed-nervous, and warm-cold. All items loaded on a single factor (explaining $49 \%$ of the variance) as indicated by a screeplot. For this reason, we combined these ratings into a single global rating score. The interrater correlation of this measure was .75 .

In a separate run, the frequencies of speech illustrators (i.e. hand or arm movements which accompany speech and which are used to emphasize what is being said) and body adaptors (i.e. touches of the own body or head) were coded with the help of a coding sheet following the recommendations by Ekman and Friesen (1972). The interrater correlations of these ratings were .78 , and .84 respectively. Visual contact was timed in a separate run with the help of a behavioral observation computer program. Coders pressed a key on the keyboard whenever. The participant gazed on the confederate's face while answering the question and released the key whenever he or she gazed away from the confederate's face. The video recording did not make it possible to distinguish between face-directed gazing and eye contact. Because participants usually looked at the confederate whenever the latter asked a follow-up question, we additionally recorded the time that the confederate spent talking and did not record visual contact during these instances. The confederate talking time was then subtracted from the total interaction time (90 s) in order to arrive at participant answering time. The percentage of visual contact was computed as the proportion of answering time participants spent gazing at the confederate, multiplied by 100 (Dovidio et al., 1997). Visual contact codings of both coders were correlated .81 .

\section{Results}

Implicit and explicit measures The means and standard deviations of IAT and BSPS scores as well as their intercorrelations are displayed in the upper part of Table 1. Attitude constructs were scaled such that higher values indicate a more positive attitude toward Africans. The Flower-Insect IAT was scaled such that higher values indicate more positive attitudes toward insects. For both the Race and the FlowerInsects IAT, negative mean effects emerged, indicating that participants responded faster when African faces and negative words shared the same response key, and when insects and negative words shared the same key, respectively. Both IATs were almost independent from each other $(r(84)=-.07, p=.50)$, hence, they did not seem to share common method-specific sources of variance (but see Mierke \& Klauer, 2003). Establishing convergent and discriminant validity of our attitude measures, the Race IAT was significantly correlated with the BSPS $(r(84)=.34, p<.001)$, but the Flower-Insect IAT was not $(r(84)=.04, p=.82)$.

Memory task For each participant, we counted the number of words correctly recalled for the first and second word list. There was no difference in memory recall between the lists $(M=8.91, S D=3.05 ; M=8.78, S D=2.98$; $t(85)=.47, p=.64)$. Furthermore, an analysis of variance (ANOVA) with memory recall as the dependent variable revealed no significant main effects or interaction as a function of position of the memory task (first or second position within confederate) and confederate race (all $F_{\mathrm{s}}<1$ ), indicating that memory performance was not affected by position and by whether participants interacted with an Italian or African confederate. 
Interviewer competence There was no significant difference in participants' competence ratings of the two African $(F(1,84)=2.07, p=.15)$, and three Italian confederates $(F(2,83)<1)$, suggesting that confederates' interview behavior was comparable. On average, African confederates were rated as competent as Italian confederates $(M=4.97, S D=1.40$ vs. $M=5.06$, $S D=1.54 ; t(85)=-.51, p=.61)$.

Question difficulty In order to check whether interview questions were equally difficult, we performed a repeated measures ANOVA on difficulty ratings with question as the withinsubjects factor. This analysis revealed a significant main effect $(F(3,246)=5.07, p=.002)$. Simple contrasts indicated that the question about cultural life $(M=3.15)$ differed significantly $(p<.05)$ from the dining hall $(M=2.48)$, living $(M=2.52)$, and quality of teaching $(M=2.76)$ questions, which did not differ significantly from each other. Thus, one caveat for the present analyses is that differences in question difficulty might have affected control resources in addition to our experimental memory task manipulation. However, as question order was orthogonal to position, memory load condition, and confederate race, these differences should not have affected the results systematically.
Behavioral observations Table 2 (upper part) summarizes the means and standard deviations for the behavioral observations separately by condition and confederate race. For each behavior, simple contrasts were computed in order to detect significant differences among means. These analyses revealed that participants gazed significantly less toward the African confederate in the memory load condition compared with all other cells. Furthermore, participants used significantly more speech illustrators toward Africans when resources were available than they did toward Italians when resources were scarce. No further reliable mean differences emerged for body adaptors and the global rating.

Following Dovidio et al. (1997) we computed relative difference scores for each behavior by subtracting the behavior displayed toward the Italian confederate (baseline) from the behavior displayed toward the African confederate separate for the memory load and full resources condition. Hence, a positive difference indicates that a participant displayed a given behavior more frequently toward the African relative to the Italian confederate.

\section{Do implicit and explicit attitudes predict} behavior differently depending on control resources? In order to test our main hypothesis

Table 2. Means and standard deviations (in parentheses) for behavioral observations in Study 1 and Study 2

\begin{tabular}{|c|c|c|c|c|}
\hline \multirow[b]{2}{*}{$\begin{array}{l}\text { Study 1: } \\
\text { Behavioral observations }\end{array}$} & \multicolumn{2}{|c|}{ Memory load condition } & \multicolumn{2}{|c|}{ Full resources condition } \\
\hline & $\begin{array}{c}\text { African } \\
\text { confederate }\end{array}$ & $\begin{array}{c}\text { Italian } \\
\text { confederate }\end{array}$ & $\begin{array}{c}\text { African } \\
\text { confederate }\end{array}$ & $\begin{array}{c}\text { Italian } \\
\text { confederate }\end{array}$ \\
\hline Visual contact & $54.13_{\mathrm{a}}(17.56)$ & $57.81_{\mathrm{b}}(17.02)$ & $57.07_{\mathrm{b}}(15.36)$ & $57.10_{\mathrm{b}}(15.51)$ \\
\hline Speech illustrators & $4.34_{\mathrm{ab}}(1.83)$ & $4.15_{\mathrm{a}}^{\mathrm{b}}(1.91)$ & $4.65_{\mathrm{b}}(1.75)$ & $4.49_{\mathrm{ab}}(2.08)$ \\
\hline Body adaptors & $1.28_{\mathrm{a}}(1.57)$ & $1.55_{\mathrm{a}}(1.69)$ & $1.30_{\mathrm{a}}(1.46)$ & $1.60_{\mathrm{a}}(1.71)$ \\
\hline Global rating & $0.66_{\mathrm{a}}(0.59)$ & $0.65_{\mathrm{a}}(0.68)$ & $0.65_{\mathrm{a}}(0.68)$ & $0.55_{\mathrm{a}}(0.59)$ \\
\hline $\begin{array}{l}\text { Study 2: } \\
\text { Behavioral observations }\end{array}$ & $\begin{array}{c}\text { Turkish } \\
\text { confederate }\end{array}$ & $\begin{array}{c}\text { German } \\
\text { confederate }\end{array}$ & $\begin{array}{c}\text { Turkish } \\
\text { confederate }\end{array}$ & $\begin{array}{c}\text { German } \\
\text { confederate }\end{array}$ \\
\hline Visual contact & $50.66_{\mathrm{ab}}(17.29)$ & $52.34_{\mathrm{ab}}(18.31)$ & $53.21_{\mathrm{a}}(17.67)$ & $49.44_{\mathrm{b}}(16.74)$ \\
\hline Speech illustrators & $5.38_{\mathrm{ab}}(5.28)$ & $4.62_{\mathrm{a}}(4.47)$ & $7.34_{c}(5.86)$ & $5.77_{\mathrm{b}}(5.02)$ \\
\hline Body adaptors & $0.76_{\mathrm{a}}(1.02)$ & $0.94_{\mathrm{a}}(1.52)$ & $0.91_{\mathrm{a}}(1.26)$ & $0.81_{\mathrm{a}}(1.33)$ \\
\hline Global rating & $0.58_{\mathrm{a}}(0.77)$ & $0.59_{\mathrm{a}}(0.75)$ & $0.73_{\mathrm{b}}(0.73)$ & $0.74_{\mathrm{b}}(0.67)$ \\
\hline
\end{tabular}

Note: Different subscripts indicate significant differences $(p<.05)$ within rows. 
that the predictive validity of implicit and explicit attitudes differs as a function of available control resources, we performed a series of repeated measures regression analyses on the various behavioral indicators, using the General Linear Model procedure for repeated measures in SPSS. In each of these equations, behavior in the memory load and in the full resources condition was the dependent variable. The continuous IAT and BSPS scores were included as simultaneous predictors. The model also specified the interaction between the within-subjects factor Condition (memory load vs. full resources) and the predictors. This procedure allowed us to estimate the standardized regression weights of the IAT and BSPS separately for the memory load and full resources conditions and to test whether regression weights differed significantly as a function of condition. According to our hypotheses and based on how variables were coded, we expected a negative interaction effect for the IAT (i.e. a reduction of predictive validity in the full resources as compared with the memory load condition) and, conversely, a positive interaction effect for the BSPS. The results of the regression analyses for Study 1 are reported in the upper part of Table 3.

Visual contact As expected, the IAT was a significant predictor of visual contact in the memory load condition, indicating that-among taxed participants, those harboring positive implicit attitudes toward Africans spent relatively more time gazing at the African interviewer than those harboring negative implicit attitudes. In the full resources condition, however, the regression weight of the IAT was negative and close to zero, consistent with our expectations. Moreover, the interaction of IAT $\times$ Condition was significantly negative $(F(1,82)=5.02, p=.028)$, indicating that regression slopes for the IAT were significantly smaller in the full resources as compared with the memory load condition. Conversely, the weight of the explicit measure was negative (but not significant) in the memory load condition and changed to positive (but not significant) in the full resources condition. As with the implicit measure, the difference between conditions was reliable as indicated by the BSPS $\times$ Condition interaction $(F(1,82)=4.49, p=.037)$.

Speech illustrators The IAT significantly predicted the frequency of speech illustrators under memory load, indicating that positive implicit attitudes were associated with more frequent use of speech illustrators to emphasize communication, but did not predict speech illustrator behavior under full resources. The difference between conditions was statistically significant $(F(1,82)=6.87, p=.010)$. However, no simple main or moderator effect was obtained for the explicit measure.

Body adaptors Contrary to our expectations, the Race IAT failed to predict body adaptors reliably in the memory load condition. As expected, BSPS scores predicted the frequency of body adaptors only when resources were available but not when resources were restrained by the memory task. The positive direction of the effect suggests that it may be best interpreted as indicating that participants with positive explicit attitudes felt more comfortable and therefore touched themselves more often in the presence of the African confederate (but see Asendorpf et al., 2002, for a different interpretation of body adaptors in the context of shyness).

Interviewer competence ratings Although it is not a behavioral measure in the strict sense, we also predicted participants' interviewer competence ratings (computed as a relative difference score) by implicit and explicit attitudes (see Table 3 ). For both the memory load and the full resources condition, this judgment was significantly related only to the explicit measure but not to the implicit measure, indicating that participants with positive explicit attitudes perceived the African confederate as more competent in relation to the Italian confederate than participants harboring negative explicit attitudes. This finding is consistent with our reasoning as the competence rating was always administered after the memory task had already been completed, i.e. at a time 
Table 3. Prediction of behavioral observations and interviewer competence ratings by implicit (IAT) and explicit (BSPS) racial attitude measures in Study 1 and Study 2 and for the combined analysis

\begin{tabular}{|c|c|c|c|c|c|c|}
\hline & \multicolumn{6}{|c|}{ Predictor } \\
\hline & \multicolumn{3}{|c|}{ IAT } & \multicolumn{3}{|c|}{ BSPS } \\
\hline & $\begin{array}{c}\beta_{\text {IAT }} \\
\text { memory } \\
\text { load }\end{array}$ & $\begin{array}{c}\beta_{\text {IAT }} \\
\text { full } \\
\text { resources }\end{array}$ & $\begin{array}{c}\eta^{2} \\
\beta_{\text {IAT }} \times \text { cond } .\end{array}$ & $\begin{array}{c}\beta_{\text {Bsps }} \\
\text { memory } \\
\text { load }\end{array}$ & $\begin{array}{c}\beta_{\mathrm{BSPS}} \\
\text { full } \\
\text { resources }\end{array}$ & $\begin{array}{c}\eta^{2} \\
\beta_{\mathrm{BSPS}} \times \text { cond }\end{array}$ \\
\hline \multicolumn{7}{|l|}{ Study 1} \\
\hline \multicolumn{7}{|l|}{ Behavioral observations } \\
\hline Visual contact & $.24 *$ & -.09 & .062 & -.18 & .12 & .053 \\
\hline Speech illustrators & $.35 * *$ & -.09 & .074 & -.10 & .00 & .004 \\
\hline Body adaptors & -.05 & .02 & .002 & .11 & $.30 *$ & .016 \\
\hline Global rating & .04 & .10 & .003 & -.06 & .10 & .017 \\
\hline Interviewer competence rating & -.01 & .01 & .000 & $.27 *$ & $.30^{*}$ & .001 \\
\hline \multicolumn{7}{|l|}{ Study 2} \\
\hline \multicolumn{7}{|l|}{ Behavioral observations } \\
\hline Visual contact & $.32 * *$ & -.07 & .094 & -.03 & .14 & .014 \\
\hline Speech illustrators & $.31 * *$ & -.06 & .084 & -.09 & -.03 & .003 \\
\hline Body adaptors & $.36 * *$ & -.15 & .156 & .01 & .01 & .000 \\
\hline Global rating & .06 & .13 & .003 & .04 & -.01 & .002 \\
\hline Interviewer competence rating & -.06 & -.06 & .000 & .15 & $.29 *$ & .018 \\
\hline \multicolumn{7}{|l|}{ Combined analysis } \\
\hline \multicolumn{7}{|l|}{ Behavioral observations } \\
\hline Visual contact & $.26 * *$ & -.08 & .063 & -.11 & .13 & .032 \\
\hline Speech illustrators & $.33 * *$ & -.07 & .083 & -.09 & -.02 & .003 \\
\hline Body adaptors & $.16^{*}$ & -.04 & .020 & .02 & $.17 *$ & .011 \\
\hline Global rating & .04 & .12 & .005 & -.01 & .04 & .002 \\
\hline Interviewer competence rating & -.03 & -.03 & .000 & $.21 * *$ & $.30 * *$ & .007 \\
\hline Global behavioral indicator & $.31 * *$ & -.02 & .072 & -.08 & $.17 *$ & .041 \\
\hline
\end{tabular}

$* p<.05 ; * * p<.01$.

Notes: All regression estimates are standardized regression weights. Significant differences in IAT (BSPS) regression weights between the memory load and full resources condition are indicated in bold. Effect size $\eta^{2}$ (partial eta squared) for each predictor $\times$ condition interaction is provided in order to indicate the percentage of variance in behavioral indicators explained by this interaction. IAT = Implicit Association Test; BSPS = Blatant Subtle Prejudice Scale; cond. = condition (memory load vs. full resources).

where resources were no longer constrained by our memory load manipulation.

Control IAT In order to examine the discriminant validity of the Race IAT and the Flower-Insect control IAT in predicting interracial interaction, we entered the Flower-Insect IAT instead of the Race IAT as the implicit predictor in the regressions above. In line with our expectation that predictive validity was restricted to the Race IAT as a thematically corresponding measure, the noncorresponding Flower-Insect IAT did not significantly predict any of the behavioral indicators in either condition, with all regression coefficients ranging between $\beta=-.15, p=.18$ and $\beta=.04, p=.70$.

\section{Discussion}

Study 1 provides initial evidence for the notion that implicit and explicit attitudes predict interracial interaction behavior differently depending on situationally available cognitive resources. Specifically, implicit attitudes as assessed with a Race IAT were reliably related to the amount 
of visual contact when participants had to perform a memory task while interacting with an outgroup member, but unrelated to gazing behavior when participants were not taxed with an additional task. Conversely, explicit attitudes were significantly more positively associated with visual contact in the full resources condition as compared to the memory load condition. Partial support was obtained with regard to speech illustrators and body adaptors. However, for these dimensions only the implicit or the explicit measure proved sensitive to our manipulation of available control resources. No predictive validity at all was obtained for judges' global ratings of interaction behavior, suggesting that global impressions may be less valid than our specific, event-oriented codings. Furthermore, the comparison with the Flower-Insect control IAT showed that the predictive validities we obtained were specific to the Race IAT, corroborating the often neglected discriminant validity of implicit attitude measures (Gawronski, 2002).

Consistent with our hypotheses, explicit but not implicit attitudes were associated with higher competence ratings of the African interviewer, independent of condition. As these ratings were always collected after the resource manipulation was finished, this result lends additional support for the hypothesis that explicit measures are better predictors of behavior when available control resources are high rather than low.

Even though there is initial support for our main predictions, the findings from Study 1 may have been limited by three possible shortcomings of our design: first, our manipulation of available control resources may have been rather weak. A second possible shortcoming is that the close temporal and local proximity of the attitude assessment and the behavioral observation phase may have made at least some of our participants suspicious of our true study goals, leading to differences in the motivation to control interracial interaction behavior. And finally, one of the questions asked was significantly more difficult than the other ones, which may have introduced additional variation in available control resources in those cases over and above our situational manipulation.

\section{Study 2}

We conducted a second study that was intended as a conceptual replication of Study 1 with the following refinements and modifications. First, we used separate measurement occasions in order to minimize potential transfer effects between predictor assessment and behavioral observation. Second, we attempted to strengthen our experimental manipulation by having participants perform an additional memory retrieval task in the memory load condition and by granting them time to prepare their answers in the full resources condition. Third, we carefully selected interview questions on the basis of pilot ratings in order to assure comparable question difficulty. Fourth, we switched to attitudes of Germans toward Turks as the content domain. In Germany, Turks constitute the largest of all foreign groups and range among the least accepted ones (Wagner, van Dick, \& Zick, 2001), making interracial interaction between Germans and Turks an appropriate content domain to identify the generalizability of our findings.

\section{Method}

Participants Seventy-seven students (27 male, 50 female) of German nationality from the University of Koblenz-Landau, between 19 and 49 years of age $(M=22.96$ years, $S D=5.59)$, participated in a longitudinal study either in exchange for course credit or 10 euros. Students were recruited from first year psychology classes $(70 \%)$ or from other departments $(30 \%)$.

Materials and procedure The study consisted of two parts. In the first session, participants completed the implicit and explicit attitude measures in this order. At least two weeks later, participants interacted with male Turkish and German confederates in an ostensibly unrelated interview practice session in a different location on campus. We used the same cover story and identical procedure as in Study 1, with the following modifications.

Implicit attitude measure A Race IAT was administered, using eight German and eight Turkish looking facial stimuli as target stimuli and eight 
positive and eight negative affective nouns as attribute stimuli (see Appendix). Target pictures were selected from pretested material used by Neumann and Seibt (2001). The number of practice and test blocks was increased to 64 trials each, such that each stimulus was presented twice per block.

Explicit attitude measure A German translation of the BSPS by Zick (1997) was used in order to measure participants' explicit attitudes toward Turks. Since all items loaded on a single main factor $(\lambda=4.88)$ as indicated by a screeplot and both subscales were again highly correlated $(r(75)=.60, p<.001)$, we computed a single BSPS index $(\alpha=.84)$.

Manipulation of control resources In the memory load condition, participants were taxed even more strongly than in Study 1 by having to generate as many words as possible starting with a ' $\mathrm{Y}$ ' or ' $\mathrm{X}$ ', in addition to the memory task adapted from Study 1. In German there are relatively few words starting with these letters, which should have led participants to continue ruminating during the interview instead of being content with the number of generated words too quickly. In the full resources condition, the experimenter handed participants a memo with the interview question wording. Participants were then granted one minute of preparation time for the interview to follow. We reasoned that being able to prepare one's answer should free up additional control resources during the interview.

Confederates The team of confederates consisted of five male German and three male Turkish confederates. The Turkish and German confederates introduced themselves with a stereotypic Turkish ('Murat') or German ('Michael') name, respectively, in order to ensure that participants categorized them according to their ethnic background.

Interview questions We pretested $(N=11)$ a variety of questions about campus life in terms of familiarity and difficulty, and selected the four questions that did not differ significantly on these dimensions (both $F \mathrm{~s}<1$ ): (a) quality and service in the dining hall, (b) equipment of the university's computer pool, (c) services and equipment of the library, and (d) quality and equipment of the lecture halls and seminar rooms.

Codings of behavior The videotaped behavior of all participants in the first 90 of their response was coded twice by a total set of four trained coders. For the analyses to follow, we averaged together both codings for each behavioral indicator. As in Study 1, we coded for visual contact (intraclass $r=.86$ between coders), speech illustrators $(r=.89)$, and body adaptors $(r=.77)$. For the global rating, the same five bipolar adjective ratings as in Study 1 were combined into a single global judgment (intraclass $r=.70)$.

Debriefing In order to ensure that during data collection all participants were naive to the true study purpose, we fully debriefed all participants via telephone after the data had been collected and gave them the opportunity to learn about their personal implicit and explicit attitude scores in our lab which most participants $(75 \%)$ utilized.

\section{Results}

Implicit and explicit measures All attitude constructs were scaled such that more positive values indicate a more positive attitude toward Turks. As can be seen from the lower part of Table 1, similar to Study 1, a negative mean effect emerged on the implicit measure, indicating that on average participants implicitly preferred German faces over Turkish faces. Unlike in Study 1, however, implicit and explicit attitudes were independent from each other $(r(75)=.004, p=.98)$.

Memory-task, interviewer competence, and question difficulty An ANOVA with memory recall (combined for the memory and the word generation task) as the dependent variable revealed no significant main effects or interaction as a function of the position of the memory task and confederate race.

As in Study 1, there was no reliable difference in competence ratings among the Turkish or 
German confederates. Furthermore, participants rated the outgroup and ingroup interviewers as equally competent on average $(M=4.58$, $S D=.90$ vs. $M=4.52, S D=.84 ; t(76)=.70$, $p=.48)$. Regarding question difficulty, a repeated measures ANOVA yielded no significant main effect $(F(3,225)<1)$, indicating that participants regarded the four questions as equally difficult.

Behavioral observations Table 2 (lower part) summarizes the means and standard deviations for the behavioral observations separately by condition and confederate race. As can be seen from a comparison of means, participants gazed slightly less toward the Turkish confederate in relation to the German confederate when put under memory load, but this difference did not reach statistical significance. However, participants spent significantly more time gazing at the Turkish relative to the German confederate in the full resources condition. Furthermore, participants used significantly more speech illustrators with regard to the Turkish interviewer when cognitively untaxed rather than taxed. Finally, the global rating was more positive with regard to both confederates in the full resources condition.

Behavior prediction by implicit and explicit attitude measures As in Study 1, we computed relative difference scores (Turkish minus German confederate) in order to control for individual differences in interaction styles. In order to investigate differential predictive validities, multiple repeated measures regression analyses were performed on behavioral indicators with IAT and BSPS scores as predictors. Again, interactions among condition and predictors were specified. Consistent with Study 1, the IAT significantly positively predicted the percentage of visual contact in the memory load condition only but not in the full resources condition, and this difference was significant $(F(1,73)=5.79$, $p=.017$ ) (see middle part of Table 3 ). The same pattern emerged with regard to the prediction of speech illustrators by our implicit measure $(F(1,73)=6.97, p=.010)$. In addition to Study 1 , the implicit measure's predictive validity with regard to the frequency of body adaptors was also moderated by available control resources $(F(1,73)=12.06, p=.001)$, such that predictive validity was high in the memory load condition and low in the full resources condition (see middle part of Table 3). Conversely, explicit attitudes toward Turks were related to interviewer competence ratings only when resources were available but,unlike in Study 1, not under memory load. As in Study 1, no significant regression weights were obtained for the prediction of the global interaction ratings.

\section{Discussion}

Study 2 lends additional support to our hypothesis that the predictive validity of implicit and explicit attitudes is moderated by situationally available control resources. Concerning our main hypothesis, as in Study 1, the percentage of visual contact and the frequency of speech illustrators were best predicted by the Race IAT when participants' control resources were limited by a memory task. In addition, the frequency of body adaptors was substantially predicted by the implicit measure under memory load. Similar to Study 1, the positive direction of the effect suggests that a higher frequency of body adaptors may be interpreted as a sign of comfort and a relaxed manner rather than as a sign of anxiety or shyness in interracial interaction. Again, the global ratings were reliably associated with neither the implicit nor the explicit measure.

Notwithstanding the many convergent results across Studies 1 and 2, there are some differences in findings that deserve special attention. First, the correlation between implicit and explicit attitude measures was significantly positive in Study 1 but zero in Study 2, and the difference between these two correlations was reliable $(z=2.21, p=.013)$. One potential explanation for this discrepancy is that German participants may have been less willing to truthfully report on their automatic reactions toward outgroup members in their explicit self-reports than Italians. A second possible explanation is that, in comparison with the Italian-African intergroup setting, German participants may harbor more 
cognitively elaborated explicit attitudes about Turks that correspond less well with more immediate affective reactions as reflected in the IAT (e.g. Hofmann, Gawronski et al., 2005).

Second, there was a different pattern of mean effects for the behavioral dimension of eye gaze between the two studies: whereas participants in Study 1 spent less time gazing at the outgroup confederate as compared to the ingroup confederate under memory load, this difference was not significant-albeit in the right direction-in Study 2. Instead, participants in Study 2 spent significantly more time gazing at the outgroup confederate when they had full resources available. This finding suggests that under full resources, German participants may have tried to convey a particularly good impression by allocating even more attention to the outgroup member, and that this favorable treatment of the outgroup member vanished when resources were situationally reduced.

Third, in order to identify reliable differences with regard to our main hypothesis of differential predictive validity, we conducted a combined analysis of both studies in which we predicted the behavioral dimensions from implicit and explicit attitudes as a function of control resources (see next section for details). Including the Study factor (Study 1 vs. Study 2) as an additional factor in these analyses showed that (a) Study did not moderate the BSPS $\times$ Condition interaction and (b) Study did not moderate the IAT $\times$ Condition interaction except in the case of body adaptors. This result reflects the fact that body adaptors were not reliably predicted by the IAT regardless of Condition in Study 1, whereas in Study 2 body adaptors were significantly predicted by the IAT, but only when control resources were scarce (see Table 3). Although we cannot offer a good explanation for this difference, this finding may indicate a cultural difference such that body adaptors may be more strongly guided by automatic processes in German participants, whereas body adaptors may be used somewhat more strategically as a means of communication by Italians (as also suggested by the significant relationship between body adaptors and the BSPS in Italians in the full resources condition).

\section{Combined analysis of Study 1 and Study 2}

The high correspondence in design and procedure of both studies enables a joint analysis of our data. Such an analysis has several advantages. First, the accumulation of data across studies strengthens the robustness and, as a consequence, the generalizability of findings. Second, the power to detect meaningful systematic variation is improved. Before combining the data from both studies, we $z$-transformed all behavioral indices and predictor measures in order to equalize the metric of the variables before pooling the data. We then performed the above regression analyses for the pooled datasets. As can be seen from the lower part of Table 3, this analysis confirmed the interaction of implicit and explicit measures with available control resources for visual contact, and also the interaction effect of the implicit measure with regard to speech illustrators. Moreover, the combined estimates across both studies indicated that the IAT predicts the frequency of body adaptors only under memory load, whereas the BSPS scale does so only when sufficient resources are available (it is important to keep in mind, however, that this is the only finding that should be generalized with caution). The global rating did not appear to be predictable by implicit and explicit measures across both studies. In line with our reasoning above, the interviewer competence rating was only predicted by the explicit measure, regardless of condition.

Finally, we combined all four behavioral observations into a broad global behavioral indicator and subjected it to a repeated measures regression analysis with IAT and BSPS scores as predictors. Overall, the implicit measure predicted the global behavioral indicator significantly in the memory load condition $(\beta=.31$, $p<.001)$, but not in the full resources condition $(\beta=-.02, p=.77)$ (see Table 3 , bottom row). Conversely, the explicit measure predicted the global indicator in the full resources $(\beta=.17$, $p=.04)$ but not in the memory load condition ( $\beta=-.08, p=.30)$. Most important, both the IAT $\times$ Condition interaction $(F(1,158)=12.33$, 
$p=.001)$, as well as the BSPS $\times$ Condition interaction $(F(1,158)=6.70, p=.011)$, were reliable. Thus, our predictions were supported on the level of the global behavioral indicator.

\section{General discussion}

The present findings on interracial interaction extend previous research on the differential predictive validity of implicit and explicit attitudes (Dovidio et al., 1997, 2002; Fazio et al., 1995; McConnell \& Leibold, 2001) by investigating the conditions under which both types of attitudes best predict behavior. Drawing on dual-process models such as the MODE model (Fazio \& Towles-Schwen, 1999) or dual-system models such as the Reflective-Impulsive Model (Strack \& Deutsch, 2004), we expected the relative behavioral impact of implicit attitudes to be stronger when situationally available control resources are low rather than high. Conversely, we expected the relative influence of explicit attitudes on behavior determination to be relatively stronger when sufficient control resources are available.

In line with these assumptions, we found across both studies that implicit racial attitudes as measured with a Race IAT predicted visual contact with an outgroup confederate better when participants were cognitively taxed than when untaxed. At the same time the predictive validity of explicit group attitudes as measured with the BSPS was more positive under full resources as compared with the memory load condition. The IAT also predicted speech illustrators reliably and more strongly under memory load than under full resources in both studies. Partially supporting our predictions, IAT scores were reliably associated with the frequency of body adaptors only in the memory load condition in German participants (Study 2), whereas BSPS scores were reliably associated with body adaptors only in the full resources condition in Italian participants (Study 1). In accordance with our hypotheses, only explicit attitudes were consistently positively related to the rating of interviewer competence which had always been administered after the memory task was completed. And finally, our framework was strongly supported on the level of the composite behavioral indicator.

By demonstrating the role of control resources as a moderator of predictive validity, our findings add an important qualification to previous research applying the taxonomy of spontaneous versus deliberative behaviors (e.g. Asendorpf et al., 2002; Dovidio et al., 1997). Instead of classifying different behaviors a priori into 'spontaneous' or 'controlled', behavior prediction may be enhanced by taking into account key moderators such as momentarily available control resources. More specifically, it is plausible to assume that control resources impose a certain threshold on how well and how many different behaviors can be simultaneously controlled by the individual. Such a view is also mirrored in the so-called resource or 'strength' model of self-regulation (e.g. Baumeister, Bratslavsky, Muraven, \& Tice, 1998), according to which control resources constitute a general and limited resource that is subject to situational and temporal fluctuation. Note that the resource model does not contradict the idea of a behavioral hierarchy in which some behaviors generally draw more heavily on available control resources than others. Rather, this model adds a dynamic element to our understanding of behavior determination in that it spells out more clearly the conditions under which automatic vs. controlled influences may be most likely expected. In the light of the present framework and findings, one could say that impulses and automatic predispositions such as implicit attitudes are not always translated into spontaneous behavior, and less so when sufficient control resources to monitor and adjust one's behavior are present. Conversely, explicit attitudes may even extend to nonverbal behaviors such as body adaptors given that sufficient control is available.

When comparing the predictive validities of implicit and explicit attitude measures in our studies, it has to be noted that-taken as a whole-the IAT appeared to be a stronger, more reliable predictor of behavior. One plausible explanation is that implicit and explicit measures may differ with regard to where they tap into the processes of behavior determination. The higher 
predictive validities of the implicit measure may be due to the fact that it assesses automatic evaluations that are directly associated with behavioral schemas of approach or avoidance (Chen \& Bargh, 1999; Neumann, Hülsenbeck, \& Seibt, 2004) which then influence behavior quite directly. In contrast, an explicit measure such as the BSPS reflects propositionally held attitudes and beliefs that may have to pass through a longer sequence of transformations (e.g. corrections, decisions, intentions) until they are finally converted into concrete action (Strack \& Deutsch, 2004). In other words, the implicit measure may be 'closer' to the behavioral output stage than the explicit measure. Developing and validating implicit and explicit measures with regard to the exact processing stages they tap into should become one of the main objectives of current attempts to link those measures to dual-process or dual-system theorizing.

The present data yield first empirical confirmation for the hypothesis that available control resources moderate the influence of implicit and explicit attitudes on actual behavior in interracial interaction. This hypothesis can be derived from a variety of existing dual-process or dual-system models in social psychology such as the MODE or the Reflective-Impulsive Model. As such, the present data undergird these models. But they do not favor one theoretical account over another. For instance, they cannot help to differentiate between a dual-process or dual-system view or to decide whether a single attitude (e.g. Fazio \& Olson, 2003) or dual attitude (e.g. Wilson et al., 2000) perspective is more appropriate. In principle, the data are consistent with any model positing that (a) implicit and explicit measures tap into different stages or systems of information processing and (b) situationally available control resources affect these different stages or systems differently such that low resources boost the influence of the stage/system implicit measures tap into. Therefore, the benefit of the present research is clearly empirical in that it tests these key assumptions with regard to actual behavior by manipulating available control resources experimentally, providing a useful starting point for future investigations.
There are several limitations of this research that should be kept in mind when generalizing the present findings to other domains and samples. First, we used only male confederates in an attempt to increase the power of our test because previous research has found that prejudiced reactions usually are stronger with regard to males than females (Eagly \& Kite, 1987). Hence, it is possible that our effects may be weaker with regard to female target persons. Second, we could not predict judges' global ratings of interaction behavior at all. One explanation for the absence of an effect is that the global rating may be based to a stronger extent on judges' subjective impressions than the easier to define and operationalize behaviors such as visual contact. Third, differences in the mean pattern of behavior utilization between the studies point to cultural differences in the usage of nonverbal behavior in interracial interaction between countries and/or as a function of specific intergroup constellations. Under memory load, Italian participants primarily reduced their visual contact with the outgroup member whereas German participants primarily cut down the frequency of speech illustrators (see Table 2). Regarding our main hypothesis (moderated predictive validity) only body adaptors appeared to be differentially influenced by implicit attitudes across studies such that body adaptors varied more strongly as a function of implicit attitudes and control resources in the German sample. The possibility of culture dependent behavior determination by implicit or explicit attitudes is an exciting avenue for future research. Taking additional settings into account may help to decompose the general patterns of behavior determination from the more cultural or intergroup-specific idiosyncrasies of interracial interaction.

Finally, our findings have applied implications as well: our results show that the causes that primarily drive interracial behavior may vary according to circumstances. For instance, implicit group attitudes or biases will most likely influence behavior when control resources are scarce. States of reduced control resources may result when people are concurrently taxed by additional tasks (as in the present studies), have 
been depleted by prior acts of self-control and are under time pressure, stress, or under the influence of alcohol. Identifying the causes (e.g. implicit vs. explicit attitudes) and the triggering conditions of impulsive or reflective intergroup behavior may eventually result in refined methods to combat prejudice and other societal problems resulting from frequent competitions among the automatic and controlled parts of human nature.

\section{Notes}

1. Disaggregating the BSPS into a blatant and subtle subscale did not affect the statistical conclusions drawn in both studies.

2. The distance between chairs was kept constant in order to control for the effects of spatial distance on eye gazing behavior (e.g. Argyle \& Dean, 1965).

3. The camera facing the interviewer did not actually record his behavior.

4. One participant did not provide a competence rating of the African interviewer for one of the questions asked; two participants did not provide one competence rating each with regard to the Italian interviewer.

\section{Acknowledgements}

This research was supported by a grant from the German Academic Exchange Service to Wilhelm Hofmann and by a grant from the German Science Foundation (DFG) to Manfred Schmitt (Schm 1092/5-1). We would like to thank Rainer Banse, Malte Friese, Bertram Gawronski, Konrad Schnabel, and Jane Thompson for valuable comments on an earlier version of this article. We also thank Valeria Adami, Gabriela Blum, Mauro Catellani, Franziska Hacke, Nina Heckmann, Gregor Roux, and Nadine Thomas for their help in collecting the data.

\section{References}

Arcuri, L., \& Boca, S. (1996). Pregiudizio e affiliazione politica: Destra e sinistra di fronte all'immigrazione dal terzo mondo [Prejudice and political affiliation: Right- and left-wing attitudes toward immigration from the third world]. In P. Legrenzi \& V. Girotto (Eds.),
Psicologia e politica [Psychology and politics] (pp. 241-274). Milano: Cortina.

Argyle, M., \& Dean, J. (1965). Eye-contact, distance and affiliation. Sociometry, 28, 289-304.

Asendorpf, J. B., Banse, R., \& Mücke, D. (2002). Double dissociation between implicit and explicit personality self-concept: The case of shy behavior. Journal of Personality and Social Psychology, 83, 380-393.

Banse, R., Seise, J., \& Zerbes, N. (2001). Implicit attitudes towards homosexuality: Reliability, validity, and controllability of the IAT. Zeitschrift für Experimentelle Psychologie, 48, 145-160.

Baumeister, R. F., Bratslavsky, M., Muraven, M., \& Tice, D. M. (1998). Ego depletion: Is the active self a limited resource. Journal of Personality and Social Psychology, 74, 1252-1265.

Chen, M., \& Bargh, J. (1999). Consequences of automatic evaluation: Immediate behavioral predispositions to approach or avoid the stimulus. Personality and Social Psychology Bulletin, 25, 215-224.

Dovidio, J. F., Kawakami, K., \& Gaertner, S. L. (2002). Implicit and explicit prejudice and interracial interaction. Journal of Personality and Social Psychology, 82, 62-68.

Dovidio, J. F., Kawakami, K., Johnson, C., \& Johnson, B. (1997). On the nature of prejudice: Automatic and controlled processes. Journal of Experimental Social Psychology, 33, 510-540.

Eagly, A. H., \& Kite, M. E. (1987). Are stereotypes of nationalities applied to both women and men? Journal of Personality and Social Psychology, 53, 451-462.

Ekman, G., \& Friesen, W. V. (1972). Hand movements. Journal of Communication, 22, 353-374.

Fazio, R. H., Jackson, J. R., Dunton, B. C., \& Williams, C. J. (1995). Variability in automatic activation as an unobtrusive measure of racial attitudes: A bona fide pipeline? Journal of Personality and Social Psychology, 69, 1013-1027.

Fazio, R. H., \& Olson, M. A. (2003). Implicit measures in social cognition research: Their meaning and uses. Annual Review of Psychology, 54, 297-327.

Fazio, R. H., \& Towles-Schwen, T. (1999). The MODE model of attitude-behavior processes. In S. Chaiken \& Y. Trope (Eds.), Dual-process theories in social psychology (pp. 97-116). New York: Guilford.

Gawronski, B. (2002). What does the Implicit Association Test measure? A test of the convergent and discriminant validity of 
prejudice related IATs. Experimental Psychology, 49, 171-180.

Greenwald, A. G., \& Banaji, M. R. (1995). Implicit social cognition: Attitudes, self-esteem, and stereotypes. Psychological Review, 102, 4-27.

Greenwald, A. G., McGhee, D. E., \& Schwartz, J. L. K. (1998). Measuring individual differences in implicit cognition: The Implicit Association Test. Journal of Personality and Social Psychology, 74, 1464-1480.

Greenwald, A. G., Nosek, B. A., \& Banaji, M. R. (2003). Understanding and using the Implicit Association Test I: An improved scoring algorithm. Journal of Personality and Social Psychology, 85, 197-216.

Hofmann, W., Gawronski, B., Gschwendner, T., Le, H., \& Schmitt, M. (2005). A meta-analysis on the correlation between the Implicit Association Test and explicit self-report measures. Personality and Social Psychology Bulletin, 31, 1369-1385.

Hofmann, W., Gschwendner, T., Nosek, B. A., \& Schmitt, M. (2005). What moderates implicitexplicit consistency? European Review of Social Psychology, 16, 335-390.

McConnell, A. R., \& Leibold, J. M. (2001). Relations among the Implicit Association Test, discriminatory behavior, and explicit measures of racial attitudes. Journal of Experimental Social Psychology, 37, 435-442.

Mierke, J., \& Klauer, K. C. (2003). Method-specific variance in the Implicit Association Test. Journal of Personality and Social Psychology, 85, 1180-1192.

Neumann, R., Hülsenbeck, K., \& Seibt, B. (2004). Attitudes toward people with AIDS and avoidance behavior: Automatic and reflective bases of behavior. Journal of Experimental Social Psychology, 40, 543-550.

Neumann, R., \& Seibt, B. (2001). The structure of prejudice: Associative strength as a determinant of stereotype endorsement. European Journal of Social Psychology, 31, 609-620.

Norman, D. A., \& Shallice, T. (1986). Attention to action. Willed and automatic control of behavior. In R. J. Davidson, G. E. Schwartz, \& D. Shapiro (Eds.), Consciousness and self regulation: Advances in research (pp. 1-18). New York: Plenum.
Nosek, B. A. (2005). Moderators of the relationship between implicit and explicit evaluation. Journal of Experimental Psychology: General, 134, 565-584.

Pettigrew, T. F., \& Meertens, R. W. (1995). Subtle and blatant prejudice in Western Europe. European Journal of Social Psychology, 25, 57-75.

Poehlman, T. A., Uhlmann, E., Greenwald, A. G., \& Banaji, M. R. (2006). Understanding and using the Implicit Association Test: 3. Meta-analysis of predictive validity. Unpublished manuscript.

Reisberg, D. (1983). General mental resources and perceptual judgments. Journal of Experimental Psychology: Human Perception and Performance, 9, 966-979.

Roediger, H. L., \& McDermott, K. B. (1995). Creating false memories: Remembering words not presented in lists. Journal of Experimental Psychology: Learning, Memory, E Cognition, 21, 803-814.

Smith, E. C., \& DeCoster, J. (2000). Dual-process models in social and cognitive psychology: Conceptual integration and links to underlying memory systems. Personality and Social Psychology Review, 4, 108-131.

Strack, F., \& Deutsch, R. (2004). Reflective and impulsive determinants of social behavior. Personality and Social Psychology Review, 8, 220-247.

Wagner, U., van Dick, R., \& Zick, A. (2001). Sozialpsychologische Analysen und Erklärungen von Fremdenfeindlichkeit in Deutschland [A social psychological analysis and explanation of hostility toward foreigners in Germany]. Zeitschrift für Sozialpsychologie, 32, 59-79.

Wilson, T. D., Lindsey, S., \& Schooler, T. Y. (2000). A model of dual attitudes. Psychological Review, 107, 101-126.

Zick, A. (1997). Vorurteile und Rassismus. Eine sozialpsychologische Analyse [Prejudice and racism: A social psychological analysis]. Münster: Waxmann.

Paper received 6 September 2006; revised version accepted 7 June 2007. 


\section{Appendix}

IAT attribute stimuli (English translation in parentheses)

Study 1

Positive words:

ALLEGRIA
AMORE
FELICITÀ
LEALTÀ
ONESTÀ
PACE
PARADISO
SIMPATIA

(cheerfulness)
(love)
(happiness)
(sincerity)
(honesty)
(peace)
(paradise)
(sympathy)

SCHIFO

OMICIDIO

DISASTRO

ODIO

ANTIPATIA

RABBIA

BOMBA

TERREMOTO

Negative words:

(disgust)
(murder)
(disaster)
(hate)
(antipathy)
(annoyance)
(bomb)
(earthquake)

Study 2

Positive words:

$\begin{array}{ll}\text { HEITERKEIT } & \text { (cheerfulness) } \\ \text { LIEBE } & \text { (love) } \\ \text { FREUDE } & \text { (happiness) } \\ \text { GESUNDHEIT } & \text { (health) } \\ \text { GLÜCK } & \text { (luck) } \\ \text { FRIEDEN } & \text { (peace) } \\ \text { PARADIES } & \text { (paradise) } \\ \text { SPASS } & \text { (fun) }\end{array}$

\section{Biographical notes}

WILHELM HOFMANN is an assistant professor at the University of Würzburg. His main research interests are in the domains of social cognition and self-regulation. Specifically, he studies the relationship between implicit and explicit attitudes and the conditions under which implicit vs. explicit attitudes influence selfregulatory behavior.

TOBIAS GSCHWENDNER is currently a PhD student at the University of Koblenz-Landau. His research interests include attitude/trait-behavior
Negative words:

ÄRGER
ELEND
ANGST
UNGLÜCK
VERRAT
STREIT
KRANKHEIT
PANIK

consistency, person $\times$ situation interactions, as well as social attitudes and prejudiced behavior. LUIGI CASTELLI is an associate professor at the University of Padova. His main areas of research include stereotyping and social perception, particularly stereotype activation and the perception of in-group members who use stereotypes.

MANFRED SCHMITT is a full professor of psychology at the University of Koblenz-Landau. His main research interests are in the domains of social justice, social emotions, altruism, and attitudebehavior consistency. 